\title{
Flexible management of heat/electricity of novel PV/T systems with spectrum regulation by Ag nanofluids
}

\author{
Chunxiao Zhang ${ }^{1}$, Chao Shen ${ }^{1 *}$, Shen $\mathrm{Wei}^{2}$, Yingbo Zhang ${ }^{1}$, Cheng Sun ${ }^{1}$ \\ ${ }^{1}$ School of Architecture, Harbin Institute of Technology, Key Laboratory of Cold Region Urban and \\ Rural Human Settlement Environment Science and Technology, Ministry of Industry and Information \\ Technology, Harbin 150090, China \\ ${ }^{2}$ The Bartlett School of Construction and Project Management, University College London (UCL), \\ London, WC1E 7HB, UK \\ *Corresponding author: Chao Shen, chaoshen@hit.edu.cn
}

\begin{abstract}
Conventional PV/T systems generally focus on maximizing electricity generation by $\mathrm{PV}$ modules only, and they do not balance the generation of electricity and heat for buildings. To match the varying energy demand of buildings, a flexible management method of novel PV/T systems with spectrum regulation was investigated by a 2D-Monte Carlo method. To maximize both electricity and heat generation, $40 \mathrm{~nm} \mathrm{Ag} /$ water nanofluid (Case 1) and 90nm Ag/water nanofluid (Case 2) have been proposed as optimal electrical and thermal nanofluids to capture solar radiation. Additionally, the influence from both mass fraction regulation and optical thickness regulation on the flexibility of the two $\mathrm{PV} / \mathrm{T}$ systems was also investigated. The results from this study indicated that increased mass fraction resulted in decreased spectral transmittances of both Ag nanofluids, with non-linear regulation of system energy output. Additionally, increased optical thickness led to reduced spectral transmittance, but with nearly linear profiles. For flexible management of PV/T systems under varying building energy demand, adjusting the optical thickness of nanofluids can be used for daily-basis optimization, while mass fraction regulation can be used for seasonally-based optimization.
\end{abstract}

Keywords: Flexible regulation, Heat-to-electric ratio, Monte Carlo method, Ag nanofluids 


\section{Nomenclature}

D Nanoparticle diameter, $(\mathrm{nm})$

$\boldsymbol{e} \quad$ Electron charge, $1.6021 \times 10^{-19} \mathrm{C}$

FF $\quad$ Fill factor of Si cell, (dimensionless)

$\boldsymbol{f}_{v, i} \quad$ Volume percentage of nanoparticle with diameter $\boldsymbol{D}$, (dimensionless)

G Solar radiation, $\left(\mathrm{W} \cdot \mathrm{m}^{-2} \cdot \mathrm{nm}^{-1}\right)$

HER Heat-to-electric ratio of PV/T systems, (dimensionless)

$I_{\lambda} \quad$ Spectral radiation along the path $s,\left(\mathrm{~W} \cdot \mathrm{m}^{-2} \cdot \mathrm{nm}^{-1}\right)$

$I_{\boldsymbol{b} \lambda} \quad$ Blackbody radiation, $\left(\mathrm{W} \cdot \mathrm{m}^{-2} \cdot \mathrm{nm}^{-1}\right)$

$\boldsymbol{I}_{\boldsymbol{s} \boldsymbol{c}} \quad$ Short circuit current, $(\mathrm{mA})$

$\boldsymbol{K}_{\boldsymbol{b}} \quad$ Boltzmann constant, $1.38 \times 10^{-23} \mathrm{~J} / \mathrm{K}$

$\boldsymbol{K}_{\text {ext }} \quad$ Extinction coefficient of nanofluids, $\left(\mathrm{cm}^{-1}\right)$

$\boldsymbol{K}_{\boldsymbol{a b s}} \quad$ Absorption coefficient of nanofluids, $\left(\mathrm{cm}^{-1}\right)$

$\boldsymbol{K}_{\text {sca }} \quad$ Scattering coefficient of nanofluids, $\left(\mathrm{cm}^{-1}\right)$

$\boldsymbol{K}_{\boldsymbol{p}, \boldsymbol{e x t}}$ Extinction coefficient of nanoparticle systems, $\left(\mathrm{cm}^{-1}\right)$

$\boldsymbol{K}_{\boldsymbol{p}, \boldsymbol{a b s}} \quad$ Absorption coefficient of nanoparticle systems, $\left(\mathrm{cm}^{-1}\right)$

$\boldsymbol{K}_{p, \text { sca }} \quad$ Scattering coefficient of nanoparticle systems, $\left(\mathrm{cm}^{-1}\right)$

$N_{i} \quad$ Nanoparticle density with diameter $\boldsymbol{D},\left(\mathrm{m}^{-3}\right)$

$\boldsymbol{P} \quad$ Survival probability of a photon, (dimensionless)

$\boldsymbol{Q}_{\text {ext }, i} \quad$ Extinction factor of single nanoparticle, (dimensionless)

$\boldsymbol{Q}_{\text {sca }, \boldsymbol{i}} \quad$ Scattering factor of single nanoparticle, (dimensionless)

SR Spectral response, $\left(\mathrm{A} \cdot \mathrm{W}^{-1}\right)$

$\boldsymbol{T}_{\text {cell }} \quad$ Cell temperature, $\left({ }^{\circ} \mathrm{C}\right)$

$V_{\text {oc }} \quad$ Open circuit voltage, (V)

\section{Greek symbol}

$\boldsymbol{\omega} \quad$ Albedo of nanoparticle, (dimensionless)

$\xi \quad$ Uniformly distributed random number between 0 and 1, (dimensionless)

$\boldsymbol{\Omega} \quad$ Solid angle, (radian)

$\boldsymbol{\eta}_{\boldsymbol{e}} \quad$ Electrical efficiency of PV/T systems, (dimensionless) 
$\boldsymbol{\eta}_{\boldsymbol{t}} \quad$ Thermal efficiency of PV/T system, (dimensionless)

$\boldsymbol{\eta}_{\boldsymbol{o}} \quad$ Overall efficiency of PV/T system, (dimensionless)

$\boldsymbol{\tau}_{\lambda} \quad$ Spectral transmittance, (dimensionless)

$\boldsymbol{\Phi}(\boldsymbol{\Theta})$ Scattering phase function of nanoparticle system, (dimensionless)

$\boldsymbol{\Phi}_{\mathbf{p}, \mathbf{i}}(\boldsymbol{\Theta})$ Scattering phase function of single nanoparticle, (dimensionless) 


\section{Introduction}

Due to the continues aggravation of energy crisis, renewable energy, such as solar energy, has been widely used in building applications in recent years $[1,2]$. Most solar-based systems, including PV modules and solar collectors, are developed to capture solar radiation and convert it into either electricity or heat for building use [3-5]. For PV modules that generate electricity only, the cell temperature has a crucial effect on their efficiency, and many studies have identified a reduction of $0.4 \%-0.5 \%$ of electrical efficiency with every $1^{\circ} \mathrm{C}$ increase of cell temperature [6, 7].

To maximize the electricity generation of PV modules, some feasible cooling technologies have been proposed to remove heat from PV modules, including fluid medium cooling, optimizing structure cooling with enhanced heat transfer, and phase change materials (PCMs) cooling [8-10]. Khanna et al. [8] have discussed the effect of solar radiation, ambient temperature, fin distance and fin width on the electricity generation PV modules integrated with PCMs, and provided some optimal structure parameters. Zhang et al. [6] have reviewed the recent development of cooling technologies for PV modules, and three types of cooling technology with 21 potential influential factors have been summarized and discussed. They suggested that nanofluids can be used to improve the energy efficiency of PV modules.

When the heat collected from PV modules was transferred to cooling medium, such as nanofluids, it can be recovered by heat exchangers for heating buildings. This composite system, called as photovoltaic/thermal systems (PV/T systems), can produce both electricity and heat simultaneously [11, 12]. Although cooling fluids have been demonstrated as an effective solution to reduce cell temperature, this 'passive cooling technology' has not solved the cooling issue fundamentally. Most cell temperature tested in existing studies was surface temperature, not actual cell temperature. Fayaz et al. [13] experimentally reported that the actual cell temperature was about $5^{\circ} \mathrm{C}$ higher than the surface temperature, with solar radiation of $1000 \mathrm{~W} / \mathrm{m}^{2}$, mass flow rate of $30 \mathrm{~L} / \mathrm{h}$, inlet temperature of $32^{\circ} \mathrm{C}$ and ambient temperature of $25^{\circ} \mathrm{C}$. For conventional PV/T systems, PV modules couple heat and electricity at the same time, acting as a combination of PV panels and solar collectors (as depicted in Figure 1a). Therefore, to fundamentally solve this issue, the energy not relevant to the solar cells should be removed, with only that solar radiation matching well with solar cells can arrive at the surface.

With the development of advanced technologies, a novel PV/T system has been proposed to intercept the energy not matching solar cells by nanofluids, and transit the matching energy to solar cells [14-17]. This 
novel system is actually a decoupled system to separate heat generation and electricity generation by spectrum regulation using nanofluids. As shown in Figure 1b, this novel PV/T system can also be considered as a combination of a direct absorption solar collector and a PV module. In this system, partial solar radiation would be absorbed by optical nanofluids, and the rest energy will be captured by solar cells to generate electricity. This novel PV/T system was firstly proposed by Taylor et al. [14], who gave some feasible solutions for spectral filtration using nanofluids. Han et al. [18] then used $\mathrm{CoSO}_{4}$-based Ag nanofluid to filter solar radiation, and indicated that there was an obvious correlation between the system's electrical efficiency and the mass fraction of nanofluids. Hassani et al. [19] discussed the difference between optical nanofluids and thermal nanofluids, and investigated the performance of a cascade nanofluid-based PV/T system. In their study, they demonstrated that the electrical efficiency of separate channel systems was about $8.6 \%$ higher than that of double-pass design systems. Zhang et al. [20] proposed some mixtures of Ag nanofluids to enhance the performance of PV/T systems, and recommended blended Ag/water nanofluid (mixed 20nm nanoparticle (80\%) with 40nm nanoparticle $(20 \%))$ as the best mixture to boost electrical efficiency. Crisostomo et al. [21] tested the use of coreshell $\mathrm{Ag}-\mathrm{SiO}_{2}$ nanofluid in $\mathrm{Si}$ solar cells, and experimentally indicated $12 \%$ increase in energy output, comparing to that with Si cell only.
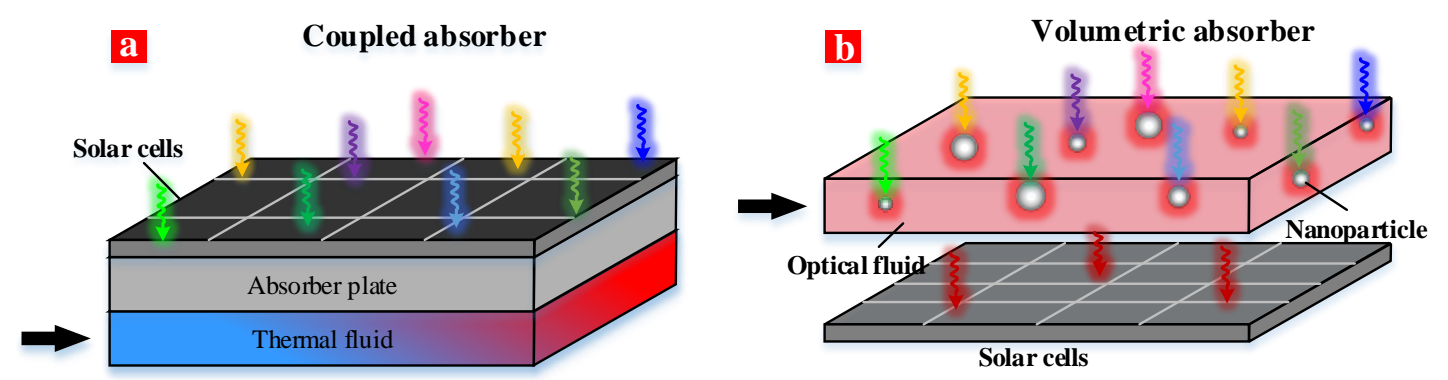

Figure 1: Schematic diagram of two PV/T systems, including (a) the traditional PV/T system, and (b) the novel PV/T system

Building energy consumption changes continusely with time, due to the changing of both indoor and outdoor environments. For northern hemisphere, due to high ambient temperature in summer, more electricity is needed to drive air conditioners in this season, with less demand on domestic hot water. In winter, however, low-temperature hot water is often needed for domestic hot water demand and underfloor heating. Due to this change of demand, a flexible electricity/heat regulation method is needed to promote the energy efficiency of PV/T systems. Conventional PV/T systems, however, focus mostly on the maximization of electricity generation, so cannot adapt to the change of energy demand in 
buildings. The novel PV/T system with spectrum regulation, however, can achieve flexible management of electricity and heat generations, by adjusting relevant parameters of optical nanofluids.

Although some work on the developed of this novel PV/T system has been found in existing literature, few studies were found to optimize its performance according to the changing demand at the building side. To realize the flexible output of this system consistent with the changing demand of building energy consumption, the flexibility of PV/T system was investigated theoretically, with a 2D-Monte Carlo method presented in Section 2 and some performance indexes proposed in Section 3.1.

\section{Methodology}

The plasmon resonance effect can enhance nanofluids' absorption on specific spectrum to boost the energy efficiency of PV/T systems. Ag nanoparticle, as one typical type of plasmon resonance particle, has been identified as a good candidate [20]. Therefore, this type of nanofluids was employed as optical nanofluid in this study, to regulate the heat and electricity generations of PV/T systems under different energy demand of buildings.

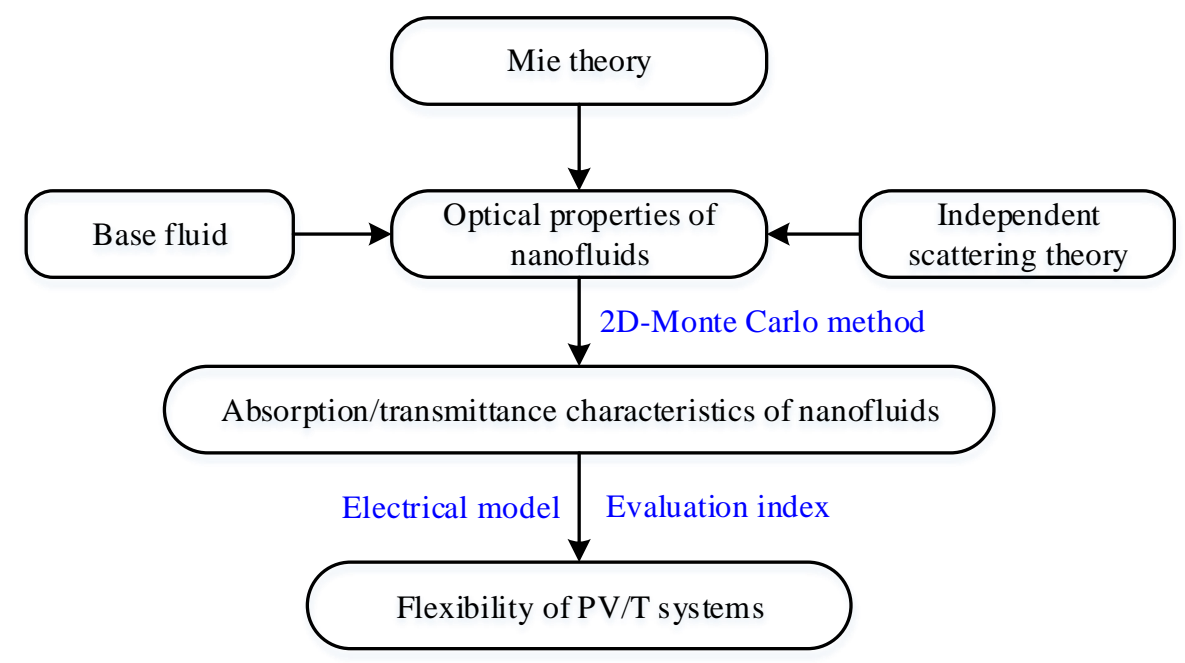

Figure 2: Flow chart of research methods

Figure 2 depicts a flow chart to indicate the research methods adopted in this study. Firstly, the Mie theory [22] was adopted to obtain the radiation properties of Ag nanoparticles. Meanwhile, the absorption properties of base fluids and the independent scattering theory were also used to get optical properties of $\mathrm{Ag}$ nanofluids. Then to theoretically investigate the matching properties between Ag nonfluids and solar cells, the transmittance of nanofluids was solved to obtain the output characteristics of solar cells. To achieve this, a 2D-Monte Carlo method has been developed in MATLAB, and validated against experimental results. In the last step, some evaluation indexes were proposed to evaluate the performance 
of PV/T systems.

\subsection{Mathematical modelling of optical properties of nanofluids}

Nanofluid is made of colloid dispersing nanoparticles uniformly into base fluids. The optical properties of nanofluids are dependent on the optical properties of both Ag nanoparticles and base fluids, including extinction coefficient $\left(\boldsymbol{K}_{\text {ext }}, \mathrm{cm}^{-1}\right)$, absorption coefficient $\left(\boldsymbol{K}_{\boldsymbol{a b s}}, \mathrm{cm}^{-1}\right)$, scattering coefficient $\left(\boldsymbol{K}_{\text {sca }}, \mathrm{cm}^{-1}\right)$ and albedo ( $\boldsymbol{\omega}$, dimensionless) of nanofluids, as shown in Equations (1)-(4) [23],

$$
\begin{gathered}
K_{e x t}=K_{p, e x t}+K_{f, e x t} \\
K_{a b s}=K_{p, a b s}+K_{f, a b s} \\
K_{s c a}=K_{e x t}-K_{a b s} \\
\omega=K_{s c a} / K_{e x t}
\end{gathered}
$$

Base fluids, such as water used in this study, are often considered as no scattering medium, with neglectable scattering coefficient. Therefore, the extinction coefficient of water equals to its absorption coefficient [24]. Meanwhile, according to the independent scattering theory, if the volume concentration of nanofluids is less than $0.6 \%$, radiative transfer can be considered as independent scattering [25]. For independent scattering, the extinction coefficient $\left(\boldsymbol{K}_{\boldsymbol{p}, \boldsymbol{e x t}}, \mathrm{cm}^{-1}\right)$, the absorption coefficient $\left(\boldsymbol{K}_{\boldsymbol{p}, \boldsymbol{a b s}}, \mathrm{cm}^{-1}\right)$, the scattering coefficient $\left(\boldsymbol{K}_{\boldsymbol{p} \text {,sca }}, \mathrm{cm}^{-1}\right)$ and the scattering phase function $(\Phi(\Theta))$ of nanoparticle systems is the sum of each nanoparticle, as followings,

$$
\begin{gathered}
K_{p, e x t}=\frac{\pi}{4} \sum_{i=1}^{n} D_{i}^{2} N_{i} Q_{\text {ext }, i}=1.5 \sum_{i=1}^{n} Q_{\text {ext }, i} \frac{f_{v, i}}{D_{i}} \\
K_{p, s c a}=\frac{\pi}{4} \sum_{i=1}^{n} D_{i}^{2} N_{i} Q_{s c a, i}=1.5 \sum_{i=1}^{n} Q_{s c a, i} \frac{f_{v, i}}{D_{i}} \\
K_{p, s c a}=K_{p, e x t}-K_{p, a b s} \\
\Phi(\Theta)=\frac{1}{K_{p, s c a}} \sum_{i=1}^{n} \frac{\pi}{4} D_{i}^{2} N_{i} Q_{s c a, i} \Phi_{p, i}(\Theta)
\end{gathered}
$$

where $\boldsymbol{N}_{\boldsymbol{i}}\left(\mathrm{m}^{-3}\right)$ is the density of nanoparticles with diameter of $\boldsymbol{D}(\mathrm{nm}) ; \boldsymbol{Q}_{\boldsymbol{e x t}, \boldsymbol{i}}$ (dimensionless), $\boldsymbol{Q}_{\text {sca, } \boldsymbol{i}}$ (dimensionless) and $\Phi_{p, i}(\Theta)$ (dimensionless) are the extinction factor, the scattering factor and the scattering phase function of single nanoparticle, and $\boldsymbol{f}_{v, i}$ (dimensionless) is the volume percentage of nanoparticle with diameter of $\boldsymbol{D}$.

For single spherical Ag nanoparticle, there are many solutions to obtain its optical properties, including 
discrete dipole approximation (DDA) [26], T-matrix [27], finite difference method [28] and Mie theory [22]. Among them, the Mie theory based on Maxwell equations has been proven in many studies, as an ideal method for solving radiation characteristics of spherical nanoparticles [22]. Therefore, this method has been employed to get radiation characteristics of single Ag nanoparticle in this study.

\subsection{A 2D-Monte Carlo method}

The radiation transfer equation, as shown in Equation (9), can be solved [23, 29], once the optical properties of nanofluids were obtained, where $\boldsymbol{I}_{\lambda}$ is the spectral radiation $\left(\mathrm{W} \cdot \mathrm{m}^{-2} \cdot \mathrm{nm}^{-1}\right)$ along the path of $\boldsymbol{s}(\mathrm{mm}), \boldsymbol{I}_{\boldsymbol{b} \lambda}$ is the blackbody radiation $\left(\mathrm{W} \cdot \mathrm{m}^{-2} \cdot \mathrm{nm}^{-1}\right), \boldsymbol{\Phi}_{\lambda}$ is the spectral scattering phase function (dimensionless) and $\boldsymbol{\Omega}$ is the solid angle (radian).

$$
\frac{d I_{\lambda}(s)}{d s}=-K_{e x t} I_{\lambda}(S)+K_{a b s} I_{b \lambda}(S)+\frac{K_{s c a}}{4 \pi} \int_{0}^{4 \pi} I_{\lambda}\left(s, \overrightarrow{\Omega^{\prime}}\right) \Phi_{\lambda}\left(\vec{\Omega}, \overrightarrow{\Omega^{\prime}}\right) d \Omega^{\prime}
$$

A 2D-Monte Carlo method [20] was used to solve the radiation transfer equation in the cuvette, and the schematic of radiation transfer of optical nanofluids was depicted in Figure 3. The spectral transmittance of optical nanofluids with a given wavelength is the ratio of photon number arriving on the surface of detectors to the total photon number ( $10^{9}$ in this study).

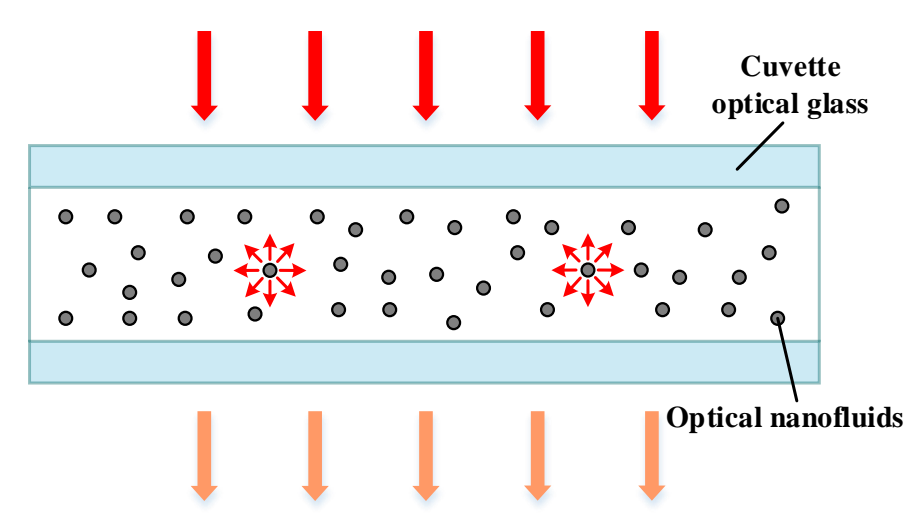

Figure 3: Schematic of radiation transfer of optical nanofluid in the cuvette

When a photon is moving in optical nanofluids, it will be either absorbed or scattered. The free path length $(\Delta \boldsymbol{s})$ is subject to the extinction coefficient of optical nanofluids, as defined by Equation (10), where $\xi_{1}$ is a uniformly distributed random number ranging between 0 and 1 .

$$
\Delta s=-\frac{\ln \left(\xi_{1}\right)}{K_{\text {ext }}}
$$

If a photon hits a nanoparticle, another uniformly distributed random number $\xi_{2}$ (also between 0 and 
1), will be set to decide whether the photon is absorbed or scattered. If $\xi_{2}$ is greater than the albedo $(\boldsymbol{\omega})$ of nanofluids, the photon would be absorbed. Otherwise it would be scattered. When the photon is scattered, the scattering phase function of Ag nanofluids would give its scattering angle. In addition, when a photon arrives at the surface of cuvette, the Fresnel reflection loss must be considered.

\subsection{Model validation}

Before the investigation of the flexibility of the novel PV/T system with spectrum regulation, the accuracy of calculated results via the 2D-Monte Carlo method, was validated with the experimental result of spectral transmittance, including deionized water and $\mathrm{Ag}$ nanofluid from Ref. [18]. In the computational process, for model validation of $\mathrm{Ag}$ nanofluid, the average nanoparticle radius was set as $25 \mathrm{~nm}$, the mass fraction was set as $5.3 \mathrm{ppm}$ and the optical thickness was set as $10 \mathrm{~mm}$. While, for deionized water validation, the absorption coefficient of deionized water was obtained from Ref. [24], the optical thickness was also set as $10 \mathrm{~mm}$, and mass fraction of $\mathrm{Ag}$ nanoparticle was set as 0 .

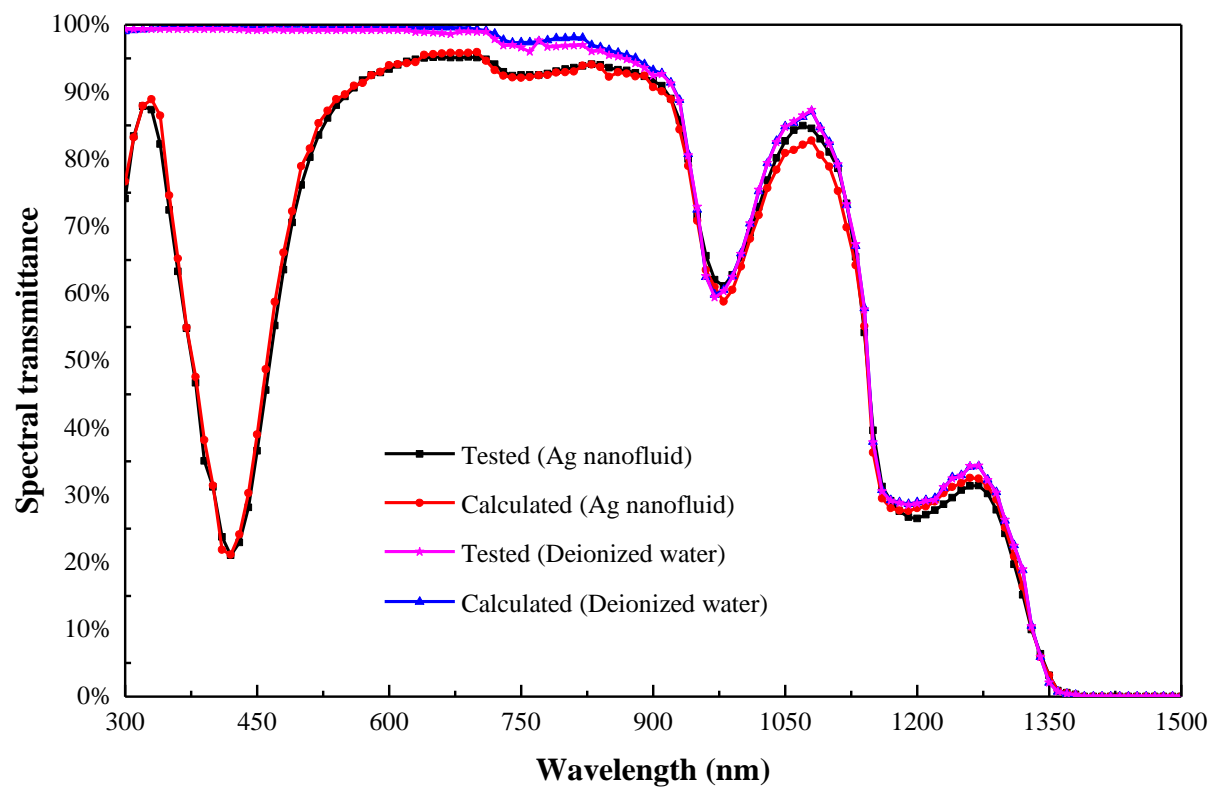

Figure 4: The comparison between spectral transmittance tested by Ref. [18] and that calculated by the

\section{D-Monte Carlo method}

Figure 4 compared the spectral transmittance obtained in Ref. [18] and that calculated by the 2D-Monte Carlo method proposed in this study, reflecting good agreements between the two data sets (i.e. tested and calculated), for both $\mathrm{Ag}$ nanofluid and deionized water. The average absolute percentage error (MAPE) and the root mean squared error (RMSE) between tested value and calculated value, were $0.47 \%$ and $0.52 \%$ for deionized water (DI water), and $2.26 \%$ and $1.41 \%$ for Ag nanofluid. 


\section{Performance evaluation indexes}

The flexibility of PV/T systems is the adjustability of system output between heat and electricity, namely, the heat-to-electric ratio. From the view of spectrum regulation, the flexibility of novel PV/T systems should be evaluated by reasonable index. For this evaluation, this section has introduced electrical efficiency (Section 3.1), thermal efficiency (Section 3.2) and heat-to-electric ratio (Section 3.3).

\subsection{Electrical efficiency}

The electrical efficiency, ( $\boldsymbol{\eta}_{\boldsymbol{e}}$, dimensionless), of PV/T systems is a key index to evaluate the system's performance, and it is calculated by open circuit voltage $\left(\boldsymbol{V}_{\boldsymbol{o} c}, \mathrm{~V}\right)$, short circuit current $\left(\boldsymbol{I}_{\boldsymbol{s} c}, \mathrm{~mA}\right)$, fill factor $\left(\boldsymbol{F F}\right.$, dimensionless) and solar radiation $\left(\boldsymbol{G}, \mathrm{W} \cdot \mathrm{m}^{-2} \cdot \mathrm{nm}^{-1}\right)$. Equation (11) shows the mathematical calculation equation for electrical efficiency, where the fill factor should be selected between 0.7 and 0.8 $[30,31]$.

$$
\eta_{e}=\frac{I_{S c} V_{o c} F F}{G}
$$

The short circuit current of Si cells is often obtained from spectral transmittance $\left(\boldsymbol{\tau}_{\lambda}\right.$, dimensionless), spectral response $\left(\boldsymbol{S} \boldsymbol{R}, \mathrm{A} \cdot \mathrm{W}^{-1}\right)$ and solar radiation $(\boldsymbol{G})$ [17]. Meanwhile, the open circuit voltage is subject to cell temperature $\left(\boldsymbol{T}_{\text {cell }},{ }^{\circ} \mathrm{C}\right)$, short circuit current and dark saturation current $\left(\boldsymbol{I}_{0}, \mathrm{~mA}\right)$. The two variables can be generated by Equations (12) and (13), where $\boldsymbol{A}^{\prime}$ is 0.99 for Si cells [19], $\boldsymbol{e}$ is the electron charge at $1.6021 \times 10^{-19} \mathrm{C}$, and $\boldsymbol{K}_{\boldsymbol{b}}$ is the Boltzmann constant at $1.38 \times 10^{-23} \mathrm{~J} / \mathrm{K}$.

$$
\begin{gathered}
I_{s c}=\int_{300}^{4000} G(\lambda) \tau(\lambda) S R(\lambda) d \lambda \\
V_{o c}=\frac{A^{\prime} k_{b} T_{c e l l}}{e} \ln \left(\frac{I_{s c}}{I_{0}}+1\right)
\end{gathered}
$$

The fill factor can be calculated by Equations (14) and (15), where $\boldsymbol{V}_{\boldsymbol{m}}$ is the voltage at the maximum power point (V) and $\boldsymbol{k}$ is chosen between 0.7 and 0.8 [19].

$$
\begin{gathered}
\mathrm{FF}=\frac{V_{m}}{V_{o c}}\left[1-\frac{\exp \left(\frac{e V_{m}}{k_{b} T_{c e l l}}\right)-1}{\exp \left(\frac{e V_{o c}}{k_{b} T_{c e l l}}\right)-1}\right] \\
V_{m}=k V_{o c}
\end{gathered}
$$

To demonstrate the accuracy of the mathematical model proposed for calculating electrical efficiency, it has been used to calculate the electrical efficiency of a reference Si cell, and the result has been compared with experimental result from Ref. [32]. With solar radiation of $1000 \mathrm{~W} / \mathrm{m}^{2}$ at AM1.5, cell temperature at 
$25^{\circ} \mathrm{C}$ and effective area of $\mathrm{Si}$ cell at $2 \mathrm{~cm} \times 2 \mathrm{~cm}$, the computational short circuit current and the open circuit voltage were $126.6 \mathrm{~mA}$ and $0.62 \mathrm{~V}$, respectively, matching well with the experimental results of $134.0 \mathrm{~mA}$ and $0.60 \mathrm{~V}$ in Ref. [32], with a relative error of $0.04 \%$.

\subsection{Thermal efficiency}

The heat generation discussed in this study was the heat absorbed by optical nanofluids, not including the heat recovery from PV modules. Therefore, the thermal efficiency ( $\eta_{t}$, dimensionless) of the novel PV/T system was calculated by Equation (16). Meanwhile, the overall efficiency ( $\eta_{o}$, dimensionless) is the sum of both electrical efficiency and thermal efficiency, as defined in Equation (17).

$$
\begin{gathered}
\eta_{t}=\frac{\int_{300}^{4000} I(\lambda)\left(1-\tau_{\lambda}(\lambda)\right) d \lambda}{G} \\
\eta_{o}=\eta_{e}+\eta_{t}
\end{gathered}
$$

\subsection{Heat-to-electric ratio}

Flexible regulation of heat and electricity, is crucial to the application for buildings. Thus, except the efficiency of PV/T systems, the heat-to-electric ratio, as a vital index of flexible regulation of heat and electricity, would be used to evaluate the flexibility of PV/T systems. The heat-to-electric ratio (HER, dimensionless) is the ratio between heat generation to electricity generation of PV/T systems, as defined by Equation (18),

$$
H E R=\frac{\int_{300}^{4000} I(\lambda)\left(1-\tau_{\lambda}(\lambda)\right) d \lambda}{I_{S c} V_{o c} F F}=\frac{\eta_{t}}{\eta_{e}}
$$

\section{Results and discussion}

To meet the changing energy demand of buildings, two Ag nanofluids were selected from the view of spectrum matching in Section 4.1. The flexible management of electricity/heat of PV/T systems was then investigated in Section 4.2 and Section 4.3, respectively, using both mass fraction regulation and optical thickness regulation.

\subsection{Optimal Ag nanofluids for maximum electricity or heat generation}

Figure 3 demonstrates the variation of the extinction factor of Ag nanoparticles with particle radius. When particle radius increased, the absorption peak of Ag nanoparticles shifted from visible region to infrared region, giving improved range of extinction factor, consistent with existing results [20, 33]. According to the principle of electromagnetic wave propagation, large nanoparticles would hinder the 
spread of the wavelength less than particle size. Additionally, due to the effect of particle size on incidence angle, the wavelength causing surface plasmon resonance increased. Thus, bigger particle size derived the movement of the absorption peak of Ag nanoparticles.

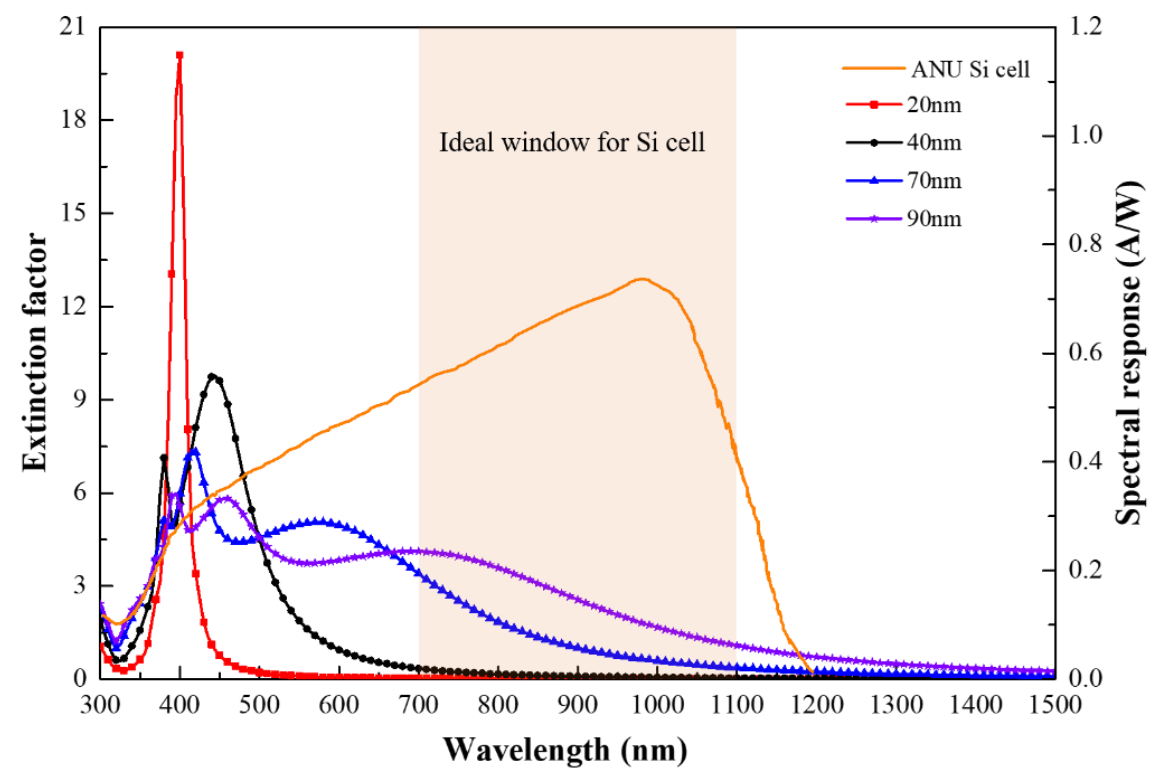

Figure 5: The extinction factor of Ag nanoparticles with particle radius, and spectral response of Si cell tested from the Australian National University (ANU) [18]

For Si cells, though the energy during 300nm-700nm, would have spectral response to Si cells, more energy is used to produce heat, leading to increased cell temperature and low electrical efficiency. Therefore, the ideal window for electricity generation was the wavelength ranging between 700nm and $1100 \mathrm{~nm}$, as justified in existing studies $[14,18]$. To maximize the electrical output of PV/T systems, the spectral energy in the ideal window should be given to Si solar cells, with the remaining energy absorbed by nanofluids to reduce cell temperature.

Ag nanoparticles with radius of 40nm can effectively absorb the energy with wavelength ranging between $300 \mathrm{~nm}$ and 700nm, allowing the rest energy penetrates. Therefore, for Ag nanofluids, the nanofluid with radius of $40 \mathrm{~nm}$ can meet the requirements to absorb unwanted heat and pass the spectral energy in ideal window simultaneously. However, to maximize thermal generation, all spectral energy needs to be collected by nanofluids and then transformed into heat. Ag nanofluid with 90nm radius can capture the energy with wavelength ranging between $300 \mathrm{~nm}$ and $1200 \mathrm{~nm}$ for thermal utilization, with the rest collected by base fluids [25], such as water, ethanol and ethylene glycol. Additionally, the Ag nanofluid with $90 \mathrm{~nm}$ radius has superior absorption characteristic for wavelength between $400 \mathrm{~nm}$ and $800 \mathrm{~nm}$, 
matching well with solar spectral energy distribution. Therefore, the Ag nanofluid with 40nm radius (Case 1) can be regarded as the optimal electrical nanofluid to maximize electricity output, and the $\mathrm{Ag}$ nanofluid with $90 \mathrm{~nm}$ radius (Case 2) can be considered as the optimal thermal nanofluid to maximize heat output. In Section 4.2 and Section 4.3, these two types of optimal nanofluid (Case 1 and Case 2) would be used to investigate the flexibility of PV/T systems.

\subsection{The effect of mass fraction on the flexible regulation of PV/T systems}

Figure 6 reports the variation of spectral transmittance and spectral radiation with optical thickness of $5 \mathrm{~mm}$. When the mass fraction of Ag nanofluid increased, both spectral transmittance and permeable spectral radiation reduced, especially for the region with higher extinction factor of Ag nanoparticles. According to the Lambert-Beer law, there is a negative correlation between mass fraction and spectral transmittance [34], meaning that increased mass fraction of Ag nanofluid would drive spectral transmittance to decrease. For Case 1, their spectral transmittance decreased obviously during the region between $300 \mathrm{~nm}$ and $700 \mathrm{~nm}$, with less reduction for the other wavelengths. Due to the higher extinction factor between 300nm and 700nm (in Figure 5), more energy was captured by the Ag nanofluid with radius of $40 \mathrm{~nm}$. However, the spectral transmittance of almost whole region (between $300 \mathrm{~nm}$ and $1300 \mathrm{~nm}$ wavelength) for Case 2 decreased, following a nearly linear profile. All spectral energy collected by the $90 \mathrm{~nm}$ Ag nanofluid, is mainly due to its high extinction factor between $300 \mathrm{~nm}$ and $1300 \mathrm{~nm}$. Certainly, the permeable spectral radiation with mass fraction regulation has shown similar trend with that of spectral transmittance.

Due to the water vapors absorption in atmosphere, the solar radiation received on the ground during the wavelength between $950 \mathrm{~nm}$ and $1100 \mathrm{~nm}$ has been attenuated greatly than that in other wavelengths [35]. Therefore, the base fluid of Ag nanofluids (water) would have negligible absorption for wavelengths ranging between $950 \mathrm{~nm}$ and $1100 \mathrm{~nm}$. 

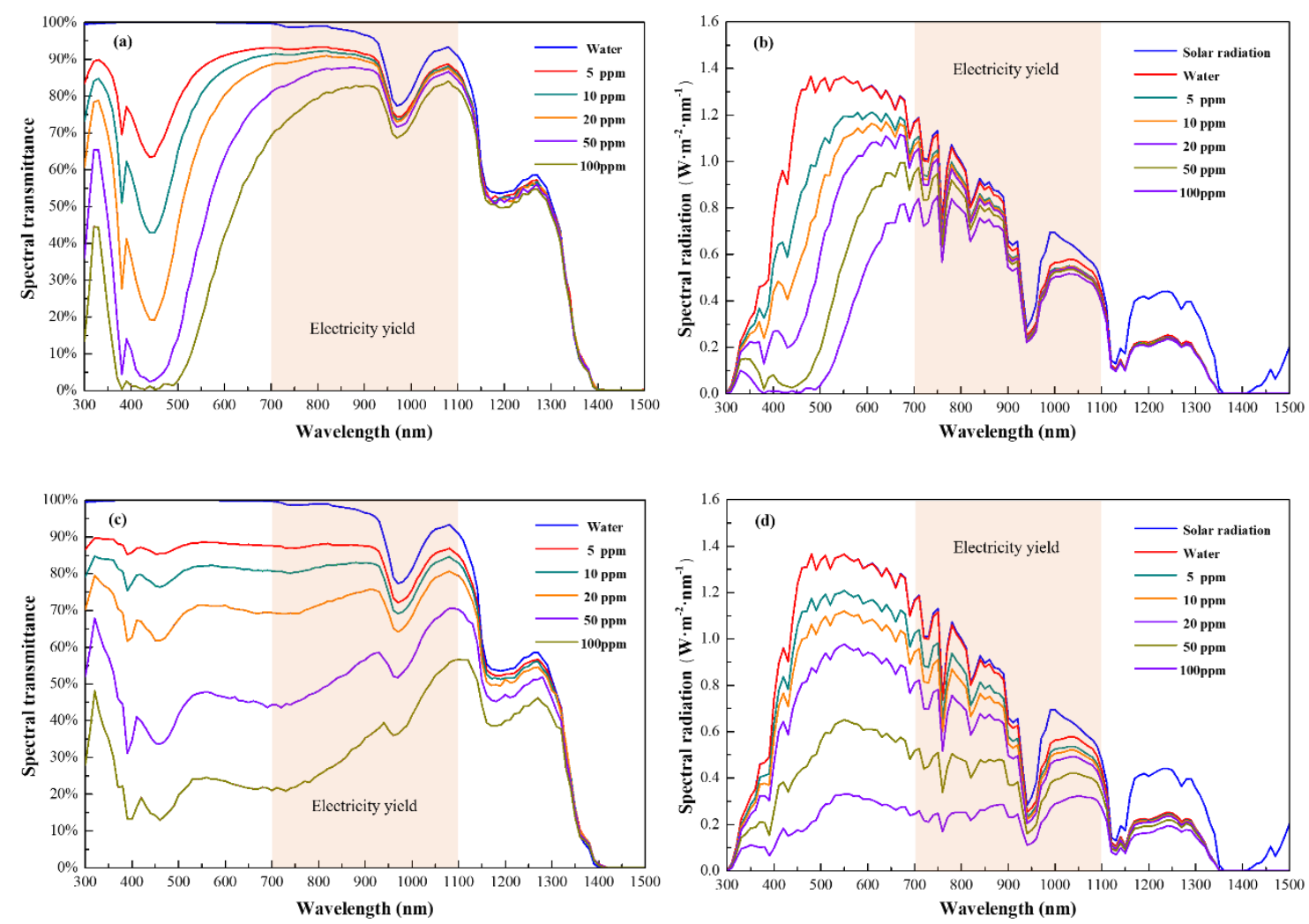

Figure 6: The variation of spectral transmittance and spectral radiation of Case 1 (a, b) and Case 2 (c,

d) with increased mass fraction

About optimal electricity generation, Case 1 with low spectral transmittance in ideal window (700nm$110 \mathrm{~nm}$ ) of Si cells was a suitable solution. The mass fraction management of Ag nanofluid would have the minimum effect on electricity generation, meaning that the Ag nanofluid with different mass fractions had an acceptable effect on electricity minimization. The integral area between spectral radiation and wavelength, as depicted in Figure 6(b), has also been called available energy for Si cells. This part energy of Case 1 during the ideal window of Si cells performed a small change for different mass fraction regulations. However, the available energy for Si cells of optimal thermal nanofluid (Case 2) decreased obviously as mass fraction increased, because most solar radiation was absorbed by the optical Ag nanofluid to produce heat.

As shown in Figure 7, increased mass fraction of Ag nanofluid would result in decreased electrical efficiency for both cases, with reduced electrical efficiency by $6.3 \%$ for Case 1 and by $11.0 \%$ for Case 2 , when the mass fraction was increasing from $0 \mathrm{ppm}$ to $100 \mathrm{ppm}$. Even though the energy during ideal window of Si cells was reserved in Case 1, the solar radiation in visible region still responded to generate electricity of Si cells. Therefore, the low spectral transmittance in this region, namely between $300 \mathrm{~nm}$ 
and $700 \mathrm{~nm}$, would decrease electricity generation, due to increased mass fraction. Meanwhile, the nanofluid with absorption at any wavelength from $300 \mathrm{~nm}$ to $1100 \mathrm{~nm}$ would lead to reduced electricity output, as supported by existing studies [20, 34, 36]. Additionally, as the optimal thermal Ag nanofluid could absorb the energy with all wavelength, the speed of reduction of electrical efficiency was higher than that of electrical Ag nanofluid.

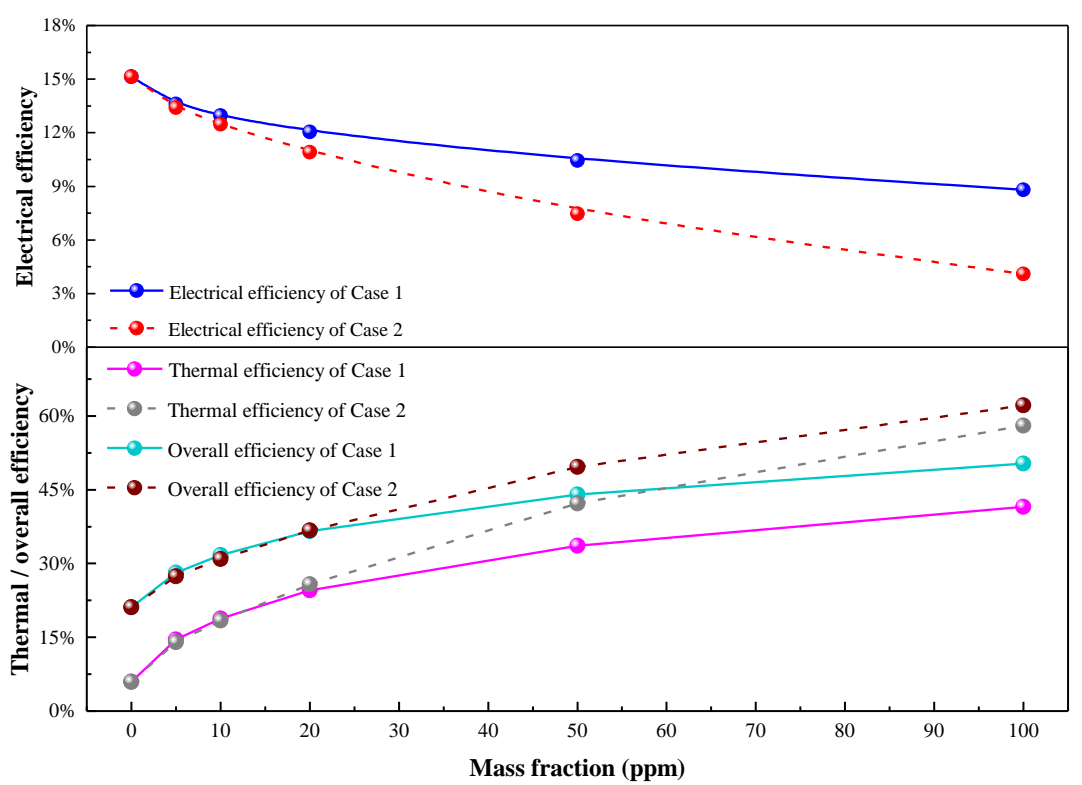

Figure 7: The performance of novel PV/T systems with mass fraction of Ag nanofluids

Contrasting to electricity efficiency, the thermal efficiency of both Ag nanofluids improved with increased mass fraction, with increased thermal efficiency by $35.6 \%$ for Case 1 and by $52.1 \%$ for Case 2, when the mass fraction was increasing from $0 \mathrm{ppm}$ to $100 \mathrm{ppm}$. A higher mass fraction of optical nanofluids would have higher spectral absorption, and therefore can collect more heat to enhance the thermal efficiency of PV/T systems. Though the electrical efficiency was reducing with increased mass fraction, the thermal efficiency improved. In other words, less electricity output can help to obtain more heating energy, which may be suitable for buildings with different needs.

Figure 8 depicts the change of heat-to-electric ratio with the mass fraction of Ag nanofluid. The heat-toelectric ratio is the ratio of heat output to electricity output of PV/T systems. Because of reduced electrical efficiency and improved thermal efficiency, the heat-to-electric ratio of both cases increased with increased mass fraction. It should be noted that, however, the increase rate of heat-to-electric ratio of Case 2 was higher than that of Case 1 . When the mass fraction was less than $20 \mathrm{ppm}$, there was no obvious difference of heat-to-electric ratio between the two cases, because of the little effect of mass fraction on the energy absorption of optical nanofluid. However, with mass fraction higher than 20ppm, the heat-to- 
electric ratio of Case 2 increased faster than that of Case 1, with the highest heat-to-electric ratio of Case 2 reached up to 14.15. For example, when the mass fraction was 50ppm, the thermal efficiency (numerator of heat-to-electric ratio) of Case 2 was higher than that of Case 1 by $8.6 \%$, and the electrical efficiency (denominator of heat-to-electric ratio) of Case 2 was lower than that of Case 1 by $2.9 \%$. This higher numerator and lower denominator of Case 2 led to higher heat-to-electric ratio.

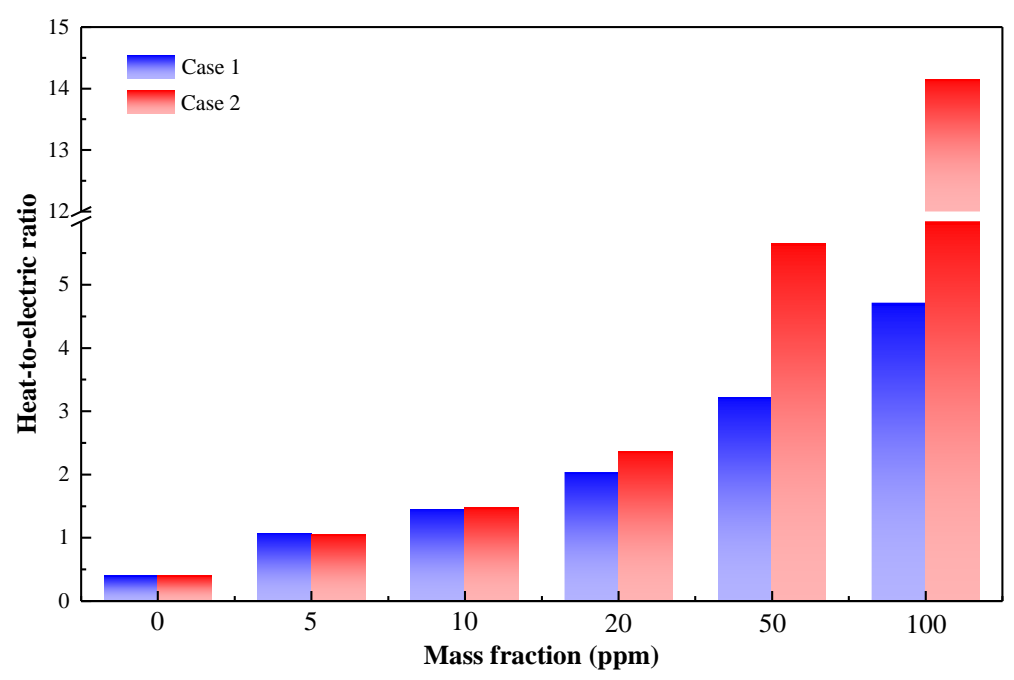

Figure 8: The variation of heat-to-electric ratio with the influence of mass fraction of Ag nanofluids When comparing the performance of the two PV/T systems with spectrum regulation using Ag nanofluid and thermal Ag nanofluid, the heat/electricity output can be regulated by changing the mass fraction of Ag nanofluid to match buildings' changing energy demand. When the building is requiring high electricity supply, the $40 \mathrm{~nm} \mathrm{Ag} \mathrm{nanofluid} \mathrm{with} \mathrm{the} \mathrm{minimum} \mathrm{thermal} \mathrm{efficiency} \mathrm{of} 5.9 \%$ and the maximum electrical efficiency of $15.1 \%$ could be used to maximize electricity output, while the $90 \mathrm{~nm}$ Ag nanofluid could be used when the building is requiring more heat.

\subsection{The effect of optical thickness on the flexible management of PV/T systems}

Figure 9 depicts the change of spectral transmittance and spectral radiation of the two cases with mass fraction of $5 \mathrm{ppm}$. When the optical thickness was increasing, both spectral transmittance and spectral radiation decreased linearly. Different from convective heat transfer, the attenuation of radiative heat transfer depends on the characteristics of optical media, including material absorption characteristic, mass fraction and optical thickness. Larger optical thickness indicates greater probability of lost photon absorbed by media. For Case 1, due to the low extinction coefficient of 40nm Ag nanofluid, the spectral transmittance during the region between $700 \mathrm{~nm}$ and $900 \mathrm{~nm}$ reduced slightly. However, since the great absorption of base fluid with negligible scattering (water) in the wavelength between $900 \mathrm{~nm}$ and $1100 \mathrm{~nm}$, 
the spectral transmittance decreased rapidly following the Lambert-Beer law [34]. In addition, the energy with wavelength bigger than 1100nm would also decrease seriously because of high absorption coefficient of water, supported by existing studies [20,25]. For Case 2, almost all spectral transmittance and permeable solar radiation decreased linearly, as 90nm Ag nanofluid can absorb energy with all wavelength, including the absorption of water. This result also demonstrated the feasibility of $90 \mathrm{~nm} \mathrm{Ag}$ nanofluid as optimal thermal nanofluid, to capture all solar radiation to enhance heat output.
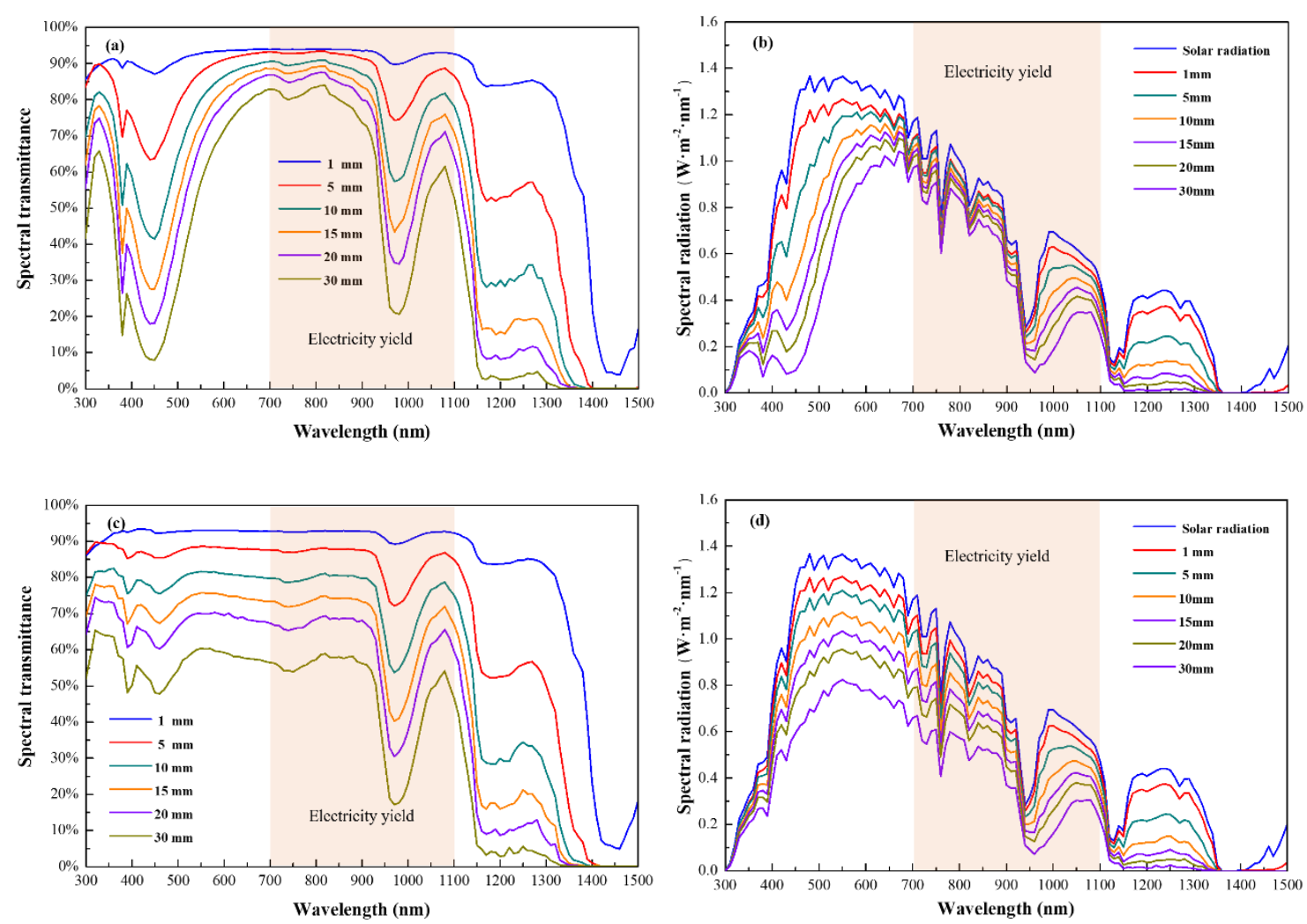

Figure 9: The variation of spectral transmittance and spectral radiation of Case $1(\mathrm{a}, \mathrm{b})$ and Case 2 (c,

d) with increased optical thickness

As shown in Figure 10, the effect of optical thickness on the electrical efficiency of Case 1 was less than that of Case 2, since more solar radiation responding to Si cells was captured by the 90nm Ag nanofluid with optical thickness regulation. In more details, the electrical efficiency of Case 1 decreased from 14.5\% to $9.6 \%$ as optical thickness increased from $1 \mathrm{~mm}$ to $30 \mathrm{~mm}$, with that of Case 2 reduced from $14.4 \%$ to $8.0 \%$. However, there was little difference between the thermal efficiency of Case 1 and Case 2, as well as the overall efficiency. Although more energy with the wavelength between $700 \mathrm{~nm}$ and $1100 \mathrm{~nm}$ was introduced to Si cells to enhance the electricity output in Case 1, the energy during 350nm to 600nm was almost absorbed by the 40nm Ag nanofluid with optical thickness regulation. Meanwhile, it's worth 
noting that the solar energy during $350 \mathrm{~nm}$ to $600 \mathrm{~nm}$ was more than $20 \%$ of whole solar energy $[18,37]$, so for same thermal efficiency, the energy collected by $40 \mathrm{~nm} \mathrm{Ag}$ nanofluid during the wavelength between $350 \mathrm{~nm}$ and $600 \mathrm{~nm}$ was nearly equal to the energy captured by the $90 \mathrm{~nm}$ Ag nanofluid during the wavelength between $300 \mathrm{~nm}$ and $900 \mathrm{~nm}$.

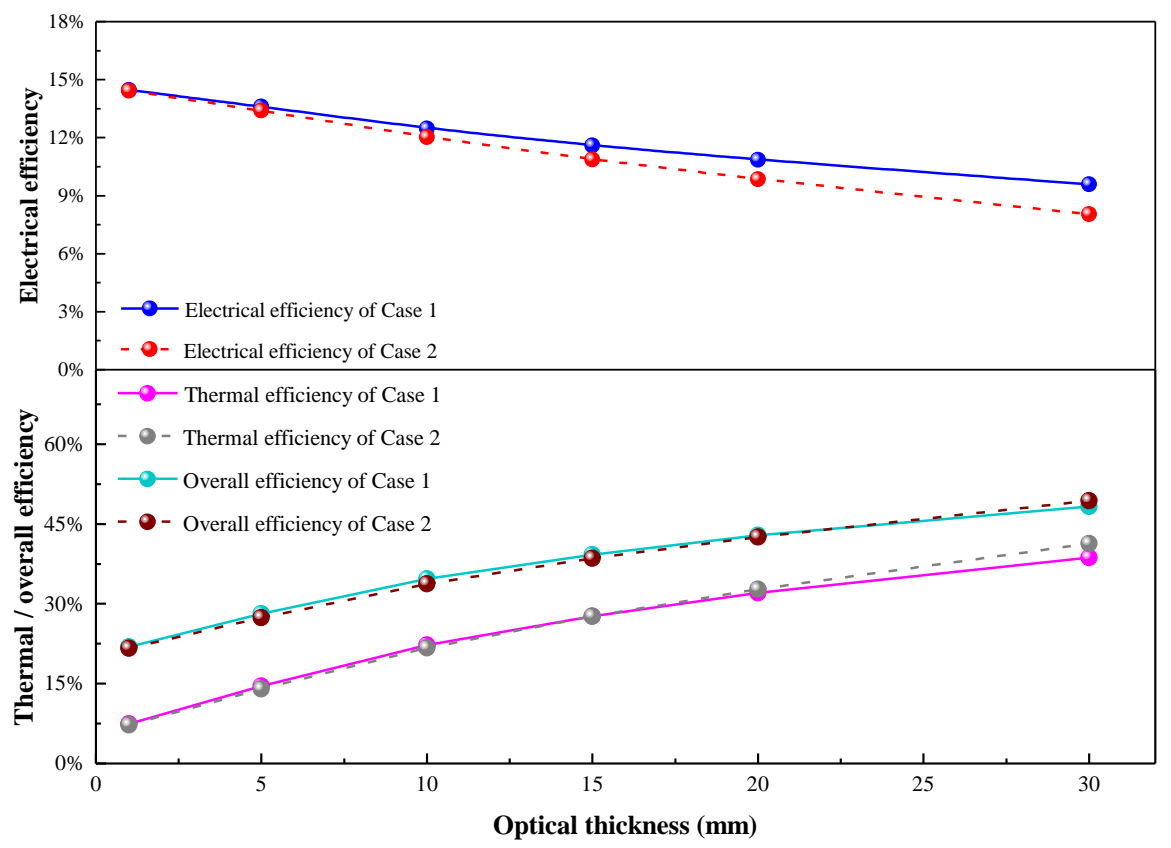

Figure 10: The performance of novel PV/T systems with optical thickness of Ag nanofluids

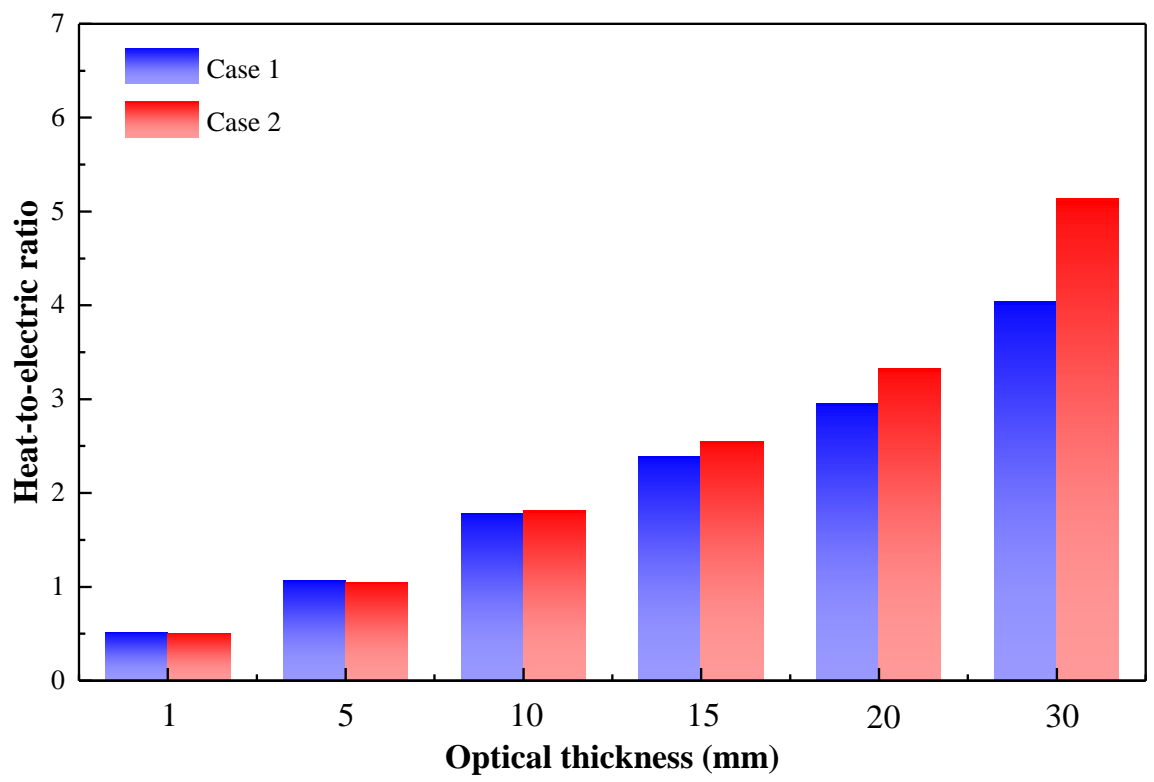

Figure 11: The heat-to-electric ratio of Case 1 and Case 2 with the influence of optical thickness of Ag nanofluids

Due to similar thermal efficiency of both cases, there was no significant difference between the heat-toelectric ratio of Case 1 and Case 2, as reported in Error! Reference source not found.. Even so, with 
optical thickness regulation, the heat-to-electric ratio of Case 2 was higher than that of Case 1, since the low electrical efficiency of Case 2. For all electrical efficiency, thermal efficiency and heat-to-electric ratio, the effect of optical thickness regulation was always near linear profiles, with that of the mass fraction regulation followed either quadratic polynomials or cubic polynomials profiles.

For buildings with changing electricity and heat demands, it is crucial to flexible manage the amounts of electricity and heat outputs from the PV/T systems, by mass fraction regulation and optical thickness regulation. According to the above discussions, flexible regulation by mass fraction was more sensitive to produce heat and electricity, especially at low mass fraction. For example, for the 40nm Ag nanofluid, when the mass fraction was increasing from $0 \mathrm{ppm}$ to $20 \mathrm{ppm}$, the electrical efficiency was reduced by $6.3 \%$ and the thermal efficiency was improved by $35.6 \%$. However, then the mass fraction was increasing from $20 \mathrm{ppm}$ to $100 \mathrm{ppm}$, the electrical efficiency was reduced only by $3.2 \%$ and the thermal efficiency was improved by just $17.0 \%$. The flexible regulation by optical thickness was easy to manage heat and electricity outputs, because of the near linear variation of three evaluation index with increased optical thickness. Therefore, from the control viewpoint, the optical thickness regulation may be more suitable than mass fraction regulation for building applications, as this linear correlation is easier to control. Of course, before managing the performance of PV/T systems by optical thickness, the optimal mass fraction must be determined according to the required building energy consumption.

\section{Conclusions}

It is well known that building energy consumption changes with time, like days and seasons. Conventional PV/T systems do not balance the generation of electricity and heat for changing demand of building energy. Thus, it is urgent to propose a PV/T system with flexible adjustment ability. To match the varying energy demand of buildings, the flexibility of a novel PV/T system with spectrum regulation has been investigated theoretically using a 2D-Monte Carlo method, with major findings summarized as followings,

(1) To match the ideal window of Si cells, the 40nm Ag nanofluid with less absorption for wavelength between $700 \mathrm{~nm}$ and $1100 \mathrm{~nm}$ was selected as optimal solution for electricity generation. From the view of regulating heat for buildings, the $90 \mathrm{~nm} \mathrm{Ag} \mathrm{nanofluid} \mathrm{with} \mathrm{full} \mathrm{spectral} \mathrm{absorption} \mathrm{was}$ adopted as optimal for thermal generation.

(2) Increasing mass fraction may result in decreased spectral transmittance for both Ag nanofluids. The 
non-linear regulation of energy generation of $\mathrm{PV} / \mathrm{T}$ systems was a main feature to mass fraction management, especially for mass fraction higher than 20ppm. Additionally, increasing optical thickness would also lead to reduced spectral transmittance, but with nearly linear profile.

(3) For flexible management of PV/T systems under varying building energy demand, adjusting the optical thickness of nanofluids can be used for daily-basis optimization, while mass fraction regulation can be used for seasonally-based optimization. The results can provide early support for the flexibility of the novel PV/T system in building integrated solar energy systems.

\section{Acknowledgement}

The authors gratefully acknowledge the funding support from the Natural Science Foundation of Heilongjiang Province (No. YQ2020E019).

\section{References}

[1] Wei W, Ni L, Xu L, Yang Y, Yao Y. Application characteristics of variable refrigerant flow heat pump system with vapor injection in severe cold region. Energy and Buildings. 2020;211:109798.

[2] Muneeshwaran M, Sajjad U, Ahmed T, Amer M, Ali HM, Wang C-C. Performance improvement of photovoltaic modules via temperature homogeneity improvement. Energy. 2020;203:117816.

[3] Gourdo L, Fatnassi H, Tiskatine R, Wifaya A, Demrati H, Aharoune A, et al. Solar energy storing rock-bed to heat an agricultural greenhouse. Energy. 2019;169:206-12.

[4] Ahmed OK, Hamada KI, Salih AM. Enhancement of the performance of Photovoltaic/Trombe wall system using the porous medium: Experimental and theoretical study. Energy. 2019;171:14-26.

[5] Yuan W, Ji J, Li Z, Zhou F, Ren X, Zhao X, et al. Comparison study of the performance of two kinds of photovoltaic/thermal(PV/T) systems and a PV module at high ambient temperature. Energy. 2018;148:1153-61.

[6] Zhang C, Shen C, Wei S, Wang Y, Lv G, Sun C. A review on recent development of cooling technologies for photovoltaic modules. Journal of Thermal Science. 2020;29(6):1410-30.

[7] Ali HM. Recent advancements in PV cooling and efficiency enhancement integrating phase change materials based systems - A comprehensive review. Solar Energy. 2020;197:163-98.

[8] Khanna S, Newar S, Sharma V, Reddy KS, Mallick TK. Optimization of fins fitted phase change material equipped solar photovoltaic under various working circumstances. Energy Conversion and Management. 2019;180:1185-95.

[9] Arya H, Sarafraz MM, Pourmehran O, Arjomandi M. Heat transfer and pressure drop characteristics of $\mathrm{MgO}$ nanofluid in a double pipe heat exchanger. Heat and Mass Transfer. 2019;55(6):1769-81.

[10] Mehmood R, Tabassum R, Pourmehran O, Ganji DD. Crosswise stream of hydrogen-oxide (H2O) through a porous media containing copper nanoparticles. International Journal of Hydrogen Energy. 2018;43(15):7562-9.

[11] Hosseinzadeh M, Salari A, Sardarabadi M, Passandideh-Fard M. Optimization and parametric analysis of a nanofluid based photovoltaic thermal system: 3D numerical model with experimental validation. Energy Conversion and Management. 2018;160:93-108.

[12] Assoa YB, Sauzedde F, Boillot B, Boddaert S. Development of a building integrated solar 
photovoltaic/thermal hybrid drying system. Energy. 2017;128:755-67.

[13] Fayaz H, Nasrin R, Rahim NA, Hasanuzzaman M. Energy and exergy analysis of the PVT system: Effect of nanofluid flow rate. Solar Energy. 2018;169:217-30.

[14] Taylor RA, Otanicar T, Rosengarten G. Nanofluid-based optical filter optimization for PV/T systems. Light: Science \& Applications. 2012;1(10):e34-e.

[15] Jin J, Jing D. A novel liquid optical filter based on magnetic electrolyte nanofluids for hybrid photovoltaic/thermal solar collector application. Solar Energy. 2017;155:51-61.

[16] Brekke N, Dale J, DeJarnette D, Hari P, Orosz M, Roberts K, et al. Detailed performance model of a hybrid photovoltaic/thermal system utilizing selective spectral nanofluid absorption. Renewable Energy. 2018;123:683-93.

[17] Hjerrild NE, Mesgari S, Crisostomo F, Scott JA, Amal R, Taylor RA. Hybrid PV/T enhancement using selectively absorbing $\mathrm{Ag}-\mathrm{SiO} 2 /$ carbon nanofluids. Solar Energy Materials and Solar Cells. 2016;147:281-7.

[18] Han X, Chen X, Wang Q, Alelyani SM, Qu J. Investigation of CoSO4-based Ag nanofluids as spectral beam splitters for hybrid PV/T applications. Solar Energy. 2019;177:387-94.

[19] Hassani S, Taylor RA, Mekhilef S, Saidur R. A cascade nanofluid-based PV/T system with optimized optical and thermal properties. Energy. 2016;112:963-75.

[20] Zhang C, Shen C, Yang Q, Wei S, Sun C. Blended Ag nanofluids with optimized optical properties to regulate the performance of PV/T systems. Solar Energy. 2020;208:623-36.

[21] Crisostomo F, Hjerrild N, Mesgari S, Li Q, Taylor RA. A hybrid PV/T collector using spectrally selective absorbing nanofluids. Applied Energy. 2017;193:1-14.

[22] Xingcai L, Kun N. Effectively predict the solar radiation transmittance of dusty photovoltaic panels through Lambert-Beer law. Renewable Energy. 2018;123:634-8.

[23] Tan J, Xie Y, Wang F, Jing L, Ma L. Investigation of optical properties and radiative transfer of TiO2 nanofluids with the consideration of scattering effects. International Journal of Heat and Mass Transfer. 2017;115:1103-12.

[24] Weber MJ. Handbook of optical materials (Section 5): CRC Press, 2003.

[25] He Q, Wang S, Zeng S, Zheng Z. Experimental investigation on photothermal properties of nanofluids for direct absorption solar thermal energy systems. Energy Conversion and Management. 2013;73:150-7.

[26] Zhang X, Yang Y, Zhang J, Li R. Scattering of an Airy light-sheet by a non-spherical particle using discrete dipole approximation. Journal of Quantitative Spectroscopy and Radiative Transfer. 2019;225:84-90.

[27] Hellmers J, Wriedt T. Applicability of T-matrix light scattering simulations for the spectral investigation of sintered nanoparticles. Journal of Quantitative Spectroscopy and Radiative Transfer. 2013;123:53-61.

[28] Wriedt T. Light scattering theories and computer codes. Journal of Quantitative Spectroscopy and Radiative Transfer. 2009;110(11):833-43.

[29] Yi H-L, Wang C-H, Tan H-P. Transient radiative transfer in a complex refracting medium by a modified Monte Carlo simulation. International Journal of Heat and Mass Transfer. 2014;79:437-49.

[30] Green MA, Emery K, Hishikawa Y, Warta W, Dunlop ED. Solar cell efficiency tables (version 44). Progress in Photovoltaics: Research and Applications. 2014;22(7):701-10.

[31] Green MA, Emery K, Hishikawa Y, Warta W, Dunlop ED. Solar cell efficiency tables (Version 45). Progress in Photovoltaics: Research and Applications. 2015;23(1):1-9. 
[32] Han X, Xue D, Zheng J, Alelyani SM, Chen X. Spectral characterization of spectrally selective liquid absorption filters and exploring their effects on concentrator solar cells. Renewable Energy. 2019;131:938-45.

[33] Ren Y, Qi H, Chen Q, Wang S, Ruan L. Localized surface plasmon resonance of nanotriangle dimers at different relative positions. Journal of Quantitative Spectroscopy and Radiative Transfer. 2017;199:4551.

[34] Ramdani H, Ould-Lahoucine C. Study on the overall energy and exergy performances of a novel water-based hybrid photovoltaic-thermal solar collector. Energy Conversion and Management. 2020;222:113238.

[35] Zhang C, Shen C, Yang Q, Wei S, Lv G, Sun C. An investigation on the attenuation effect of air pollution on regional solar radiation. Renewable Energy. 2020;161:570-8.

[36] Crisostomo F, Taylor RA, Surjadi D, Mojiri A, Rosengarten G, Hawkes ER. Spectral splitting strategy and optical model for the development of a concentrating hybrid PV/T collector. Applied Energy. 2015;141:238-46.

[37] Mohammadnia A, Rezania A, Ziapour BM, Sedaghati F, Rosendahl L. Hybrid energy harvesting system to maximize power generation from solar energy. Energy Conversion and Management. 2020;205:112352. 